\title{
Room Temperature Multifunctional Organophosphorus Gels and Liquid Crystals
}

\author{
Carlos Romero-Nieto, Mercedes Marcos, Sonia Merino, Joaquín Barberá, \\ Thomas Baumgartner, * and Julián Rodríguez-López*
}

A new series of extended dithieno[3,2-b:2',3'-d]phospholes with dendritic and non-dendritic architectures involving phenylenevinylene as well as Fréchettype dendrons is presented. Modification of the phosphorus center with Pd allows for the generation of a dimeric dendrimer with Pd-center. The synthetic strategy employed balances the rigid main scaffold with the flexibility of the dendrons in order to keep control of supramolecular self-organization features. All the structures show a high photoluminescence in both solution and solid state, which is further intensified via energy transfer from the dendrons to the core. In terms of self-organization in solution, three of the derivatives which bear an extended phosphole unit as common moiety are able to gel a variety of organic solvents at room temperature independently from the nature of their substituents. Notwithstanding, the dimeric dendrimer with Fréchet-type dendrons is only able to display gel properties at low temperature. All gels exhibit pronounced photoluminescence properties that can be tuned by variation of the solvent and the temperature. In absence of solvent, the phosphole derivatives exhibit, moreover, liquid-crystalline mesomorphism features. While three of the compounds present stable and highly luminescent columnar hexagonal phases at room temperature, the fourth species was found to be crystalline in the thermal range up to its isotropic state. Finally as proof of concept, the multifunctionality of these materials is demonstrated in an electrochromic device.

\section{Introduction}

Hierarchically multiordered structures of natural materials play a fundamental role in life bioarchitectures. In materials science, the supramolecular organization of organic/inorganic

Dr. C. Romero-Nieto, Dr. S. Merino, Dr. J. Rodríguez-López Facultad de Química

Universidad de Castilla-La Mancha 13071-Ciudad Real, Spain E-mail: julian.rodriguez@uclm.es

Prof. T. Baumgartner

Department of Chemistry

University of Calgary, 2500 University Drive NW

Calgary, AB T2N 1N4, Canada

E-mail: thomas.baumgartner@ucalgary.ca

Dr. M. Marcos, Dr. J. Barberá

Departamento de Química Orgánica-Instituto de Ciencia de los

Materiales de Aragón Universidad de

Zaragoza-CSIC 50009-Zaragoza, Spain

DOI: 10.1002/adfm.201101219 molecules is also of significant importance since it determines the physical properties of bulk materials and their potential use in specialty applications. Although a great deal of research effort has been invested in mastering the bottom-up self-organization of multifunctional molecules, i.e. designing the molecular architectures attempting to comprehensively control their supramolecular features (interactions, orientation, packing, etc.), ${ }^{[1]}$ this task still represents an ambitious challenge to accomplish. Among the three dimensional (3D) assemblies of synthetic materials, liquid crystals (LCs) and supramolecular gels have recently attracted considerable attention. Liquid crystalline materials exhibit highly ordered and dynamic structures that bring about exceptional charge carrier mobilities (up to $0.1-1.3 \mathrm{~cm}^{2} \mathrm{~V}^{-1} \mathrm{~s}^{-1}$ ), ${ }^{[2]}$ as well as anisotropic properties. ${ }^{[3]}$ These features have been found to open up intriguing opportunities for highly topical research areas such as solar cells, ${ }^{[4]}$ light-emitting diodes, ${ }^{[5]}$ low-dimensional charge-, ${ }^{[2 \mathrm{~d}, 6]}$ ion-, ${ }^{[7]}$ and mass-transporting ${ }^{[8]}$ materials. Supramolecular gels, on the other hand, are colloidal semisolid 3D-networks that exhibit stimuli-dependent physical properties. ${ }^{[9]}$ Interestingly moreover, some features of the bulk material, like for example the photoluminescence of molecular gelators, can also be modulated by controlling the intermolecular interactions ${ }^{[10]}$ as well as the orientation of the 3D-networks. ${ }^{[11]}$ These interesting phenomena, along with the ability to trap and immobilize large volumes of solvent and even small molecules, have allowed gels to be implemented in a large array of diverse applications such as drug delivery, tissue engineering, electronics, fluorescent imaging, lithography, sensors, and catalysts, to name just a few. ${ }^{[12]}$ Despite the different environmental nature of LCs and gels (viscous solid and colloidal suspension), both of these supramolecular assemblies are known to be the result of a complex balance between non-covalent attractive forces arising from a rigid scaffold ( $\pi-\pi$ stacking, anisotropic dispersion forces, van der Waals interactions and hydrogen bonds), and the disorder introduced by flexible moieties. ${ }^{[13]}$

Among the aromatic heteroles, phospholes have experienced a rapid evolution in the recent years. ${ }^{[14]}$ These phosphorus-based, five-membered heterocycles possess unique 
<smiles>[2H]c1cc(/C=C/c2cc3c(s2)-c2sc(/C=C/c4cc([2H])c(P)c(P)c4)cc2P3(=O)c2ccccc2)cc(P)c1P</smiles>

1

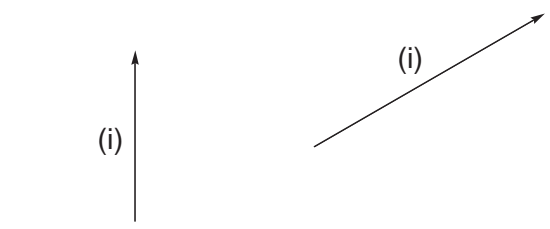<smiles>O=Cc1cc2c(s1)c1sc(C=O)cc1p2-c1ccccc1</smiles><smiles>[2H]c1cc(/C=C/c2cc(C)cc(/C=C/c3cc([2H])c(P)c(P)c3)c2)cc(P)c1[2H]</smiles><smiles>CC1CCCCC1</smiles><smiles>[2H]c1cc(/C=C/c2cc(/C=C/C(=C)C)cc(/C=C/c3cc([2H])c(P)c(P)c3)c2)cc(P)c1P</smiles>

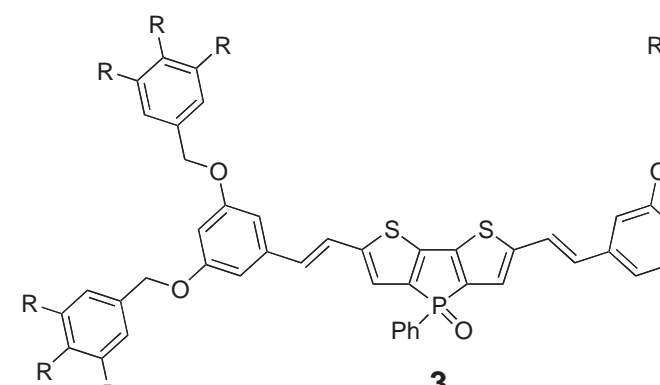<smiles>[2H]c1cc(COc2cccc(OCc3cc(P)c(P)c(P)c3)c2)cc(P)c1P</smiles><smiles>[2H]c1cc(CCl)cc(P)c1P</smiles>

\section{$\mathrm{R}=\mathrm{OC}_{12} \mathrm{H}_{25}$}

Scheme 1. Synthesis and chemical structures of compounds 1-4. Reagents: (i) 1. $\mathrm{Ar}_{-} \mathrm{CH}_{2}-\mathrm{P}(\mathrm{O})(\mathrm{OEt})_{2}, t \mathrm{BuOK}, \mathrm{then}_{2} \mathrm{H}_{2} \mathrm{O}_{2}$; (ii) $1 . \mathrm{BH}_{3} \cdot \mathrm{SMe}_{2}$, 2. Et $\mathrm{N}_{3} \mathrm{~N}$, 3. $\left[\mathrm{Pd}(\mathrm{COD}) \mathrm{Cl}_{2}\right]$.

structural and electronic features that distinguish them from other main group heteroles. Phospholes present a particularly low-lying LUMO due to the effective interaction of the $\sigma^{*}$ (P-R exocyclic)- $\pi^{*}$ (1,3-diene) orbitals, and the phosphorus center adopts a pyramidal geometry holding an electron lone pair with high $s$ character. ${ }^{[15]}$ Consequently, these phosphorusbased heterocycles exhibit a considerable electron affinity and the orbital energies can moreover be readily fine-tuned by means of simple functionalization at the phosphorus atom through oxidation agents, transition metals, or Lewis acids. ${ }^{16]}$ These features, together with the extraordinary and tunable optical properties found in some phospholebased systems, ${ }^{[14 a-c, 17]}$ make these heterocycles particularly appealing for the development of new molecular architectures. To date, phosphole heterocycles have been successfully applied in coordination chemistry, ${ }^{[15 f, 17 e, 18]}$ in the synthesis of new fused heterocycles, ${ }^{[14 b-c, 14 i, 17 c, 19]}$ in phosphaporphyrins, ${ }^{[20]}$ polymers ${ }^{[21]}$ and dendrimers. ${ }^{[22]}$ We could recently establish that extended star-shaped dithieno[3,2-b:2', $\left.3^{\prime}-d\right]$ phospholes have the ability to self-assemble into large and rigid one-dimensional (1D) microfibers by $\pi-\pi$ stacking. ${ }^{[22 a]}$
Encouraged by this observation, we envisaged the possibility of engineering the self-assembly behavior of dendritic phosphole-cored derivatives, with the aim of obtaining dynamic and well ordered supramolecular structures, such as gels and/or liquid crystals. It is important to note that, to the best of our knowledge, no studies on multifunctional and highly luminescent gels and liquid crystalline materials based on these P-heterocycles have been reported to date.

Herein we now report on the design, synthesis, photophysical, and self-assembly properties of a series of new dendritic and non-dendritic multifunctional phosphole derivatives (see Scheme 1). These photoluminescent materials are found to exhibit the ability to gel organic solvents at different transition temperatures. The spectroscopic investigation reveals that the use of different solvents and/or temperatures allows modulating the emissive properties of the gel phases. Moreover, in the solid state these molecules are also capable of self-assembly into highly luminescent and room temperature liquid crystals. This investigation sheds light on the potential applicability of the phosphole-based molecules as promising multifunctional materials. 
Table 1. Spectroscopic data of compounds $1-4\left(c \approx 10^{-6} \mathrm{~mol} \mathrm{~L}^{-1} ; T=298 \mathrm{~K}\right)$.

\begin{tabular}{|c|c|c|c|c|c|c|}
\hline Compd & Solvent & $\begin{array}{c}\lambda_{\text {abs }} \\
{[\mathrm{nm}]^{\mathrm{a})}}\end{array}$ & $\begin{array}{c}\varepsilon \\
{\left[\mathrm{M}^{-1} \mathrm{~cm}^{-1}\right]^{b)}}\end{array}$ & $\begin{array}{c}\lambda_{\mathrm{em}} \\
{[\mathrm{nm}]^{\mathrm{c})}}\end{array}$ & $\begin{array}{c}E T \\
{[\%]^{d)}}\end{array}$ & $\begin{array}{l}\text { QY } \\
{[\%]^{\mathrm{e}}}\end{array}$ \\
\hline \multirow[t]{4}{*}{1} & THF & 347,472 & 20500,26200 & 569 & & 22 \\
\hline & $\mathrm{CH}_{2} \mathrm{Cl}_{2}$ & 349,477 & & 576 & & \\
\hline & Hexanes & 345,468 & & 560 & & \\
\hline & solid state & & & 599 & & \\
\hline \multirow[t]{4}{*}{2} & THF & 330,452 & 108600,23700 & 423,547 & 64 & 24 \\
\hline & $\mathrm{CH}_{2} \mathrm{Cl}_{2}$ & 331,463 & & 429,555 & 75 & \\
\hline & Hexanes & 328,445 & & 402,581 & 66 & \\
\hline & solid state & & & 597 & & \\
\hline \multirow[t]{4}{*}{3} & THF & $272,335,458$ & $36000,26200,22800$ & 552 & 77 & 23 \\
\hline & $\mathrm{CH}_{2} \mathrm{Cl}_{2}$ & $274,337,463$ & & 555 & 84 & \\
\hline & Hexanes & $272,332,449$ & & 562 & 69 & \\
\hline & solid state & & & 585 & & \\
\hline \multirow[t]{4}{*}{4} & THF & $273,329,377$ & $71300,42200,42200$ & 499 & 69 & 26 \\
\hline & $\mathrm{CH}_{2} \mathrm{Cl}_{2}$ & $271,338,380$ & & 506 & 81 & \\
\hline & Hexanes & $272,340,369$ & & 539 & 89 & \\
\hline & solid state & & & 547 & & \\
\hline
\end{tabular}

a) Peak absorption maxima; b) Molar extinction coefficient; ${ }^{c}$ Emission maxima. Excited at the longest $\lambda_{\text {abs }}$ maxima for $\mathbf{1}$, and at the shortest $\lambda_{\text {abs }}$ maxima for $2-4$; ${ }^{d)}$ Energy transfer efficiency; e) Fluorescence quantum yield relative to rhodamine $6 \mathrm{C}$ (in water, $\lambda_{\mathrm{ex}}=488 \mathrm{~nm}$ ) for compounds $1-3$, and relative to anthracene (in ethanol, $\lambda_{\mathrm{ex}}=$ $356 \mathrm{~nm}$ ) for compound 4 .

\section{Results and Discussion}

\subsection{Synthetic Strategy}

The initial focus of our systematic approach was on balancing the ratio between the rigid main scaffold/flexible moieties in order to control the supramolecular assembly. Compound 1 (Scheme 1) was designed with a relatively small $\pi$-extended central area, surrounded by six terminal dodecyloxy chains in order to govern the supramolecular self-organization. In case the attractive intermolecular $\pi-\pi$-interactions resulting from the main scaffold were not strong enough to direct the stacking of molecules, the first generation poly(phenylenevinylene) (PPV) dendrimer 2 with a larger rigid central framework and dodecyloxy terminal chains as flexible moieties was also synthesized (Scheme 1). Furthermore, in the event of the terminal chains not being able to confer enough flexibility to drive the supramolecular arrangement, compound 3 with Fréchet-type dendrons, i.e., flexible 3,4,5-trisubstituted benzyloxy terminal groups, was also considered. Finally, taking advantage of the phosphorus chemistry, a palladium-bridged dimeric structure (compound 4) was also derived from compound 3. The envisaged flexibility of such a dendrimer as a whole, together with the restricted discotic shape was thought to be worthy of comparison with the monomeric structures. The target molecules 1,2 , and 3 were synthesized according to a modified Wittig-Horner procedure reported by us earlier, ${ }^{[22 a]}$ using the 2,6-diformyldithieno[3,2-b:2',3'-d]phosphole and the appropriate phosphonates (Scheme 1). The dendritic Pd-bridged dimer 4 was prepared from the compound 3 by means of a reaction sequence involving the reduction of compound 3 and subsequent treatment with half an equivalent of $[\operatorname{Pd}(C O D)$ $\left.\mathrm{Cl}_{2}\right] \cdot{ }^{[17 \mathrm{e}]}$ The synthetic procedures are detailed in the Supporting Information.

\subsection{Photophysical Properties}

The new materials reported herein showed some interesting photophysical properties. The absorption and emission spectra of compounds 1-4 were recorded in different solvents as well as in the solid state. The data are summarized in Table 1.

All compounds show a similar trend in their absorption maxima. In general, a positive solvatochromism was observed upon changing from hexanes (the least polar solvent) to $\mathrm{CH}_{2} \mathrm{Cl}_{2}$ (see Supporting Information (SI), Figures S1-S4). Surprisingly, a different behavior was observed on changing from $\mathrm{CH}_{2} \mathrm{Cl}_{2}$ to THF. The use of THF (an oxygen-containing solvent more polar than $\mathrm{CH}_{2} \mathrm{Cl}_{2}$ ) led to absorption maxima at shorter wavelengths, which points to the presence of different solute/solvent interactions. ${ }^{[23]}$

By contrast, a regular trend was found in the emission properties. An increase in solvent polarity led to hypsochromic shifts of the emission maxima of the dendritic materials 2-4 (see SI). This fact suggests that the interaction of the dipole moment with polar solvents lowers the energy of the ground state more than that of the emissive excited state, giving rise to blue-shifted emission bands. ${ }^{[24]}$

Figure 1 shows the optical spectra of the compounds 1-4 in THF solutions (see SI for $\mathrm{CH}_{2} \mathrm{Cl}_{2}$ and hexanes solutions, Figures S1-S4). Compound 1, with six peripheral dodecyloxy donor chains, presents two main characteristic absorption bands (at $\lambda_{\max }=347 \mathrm{~nm}$ and $\lambda_{\max }=472 \mathrm{~nm}$ ) as previously observed in analogous extended phenylenevinylene dithienophosphole 

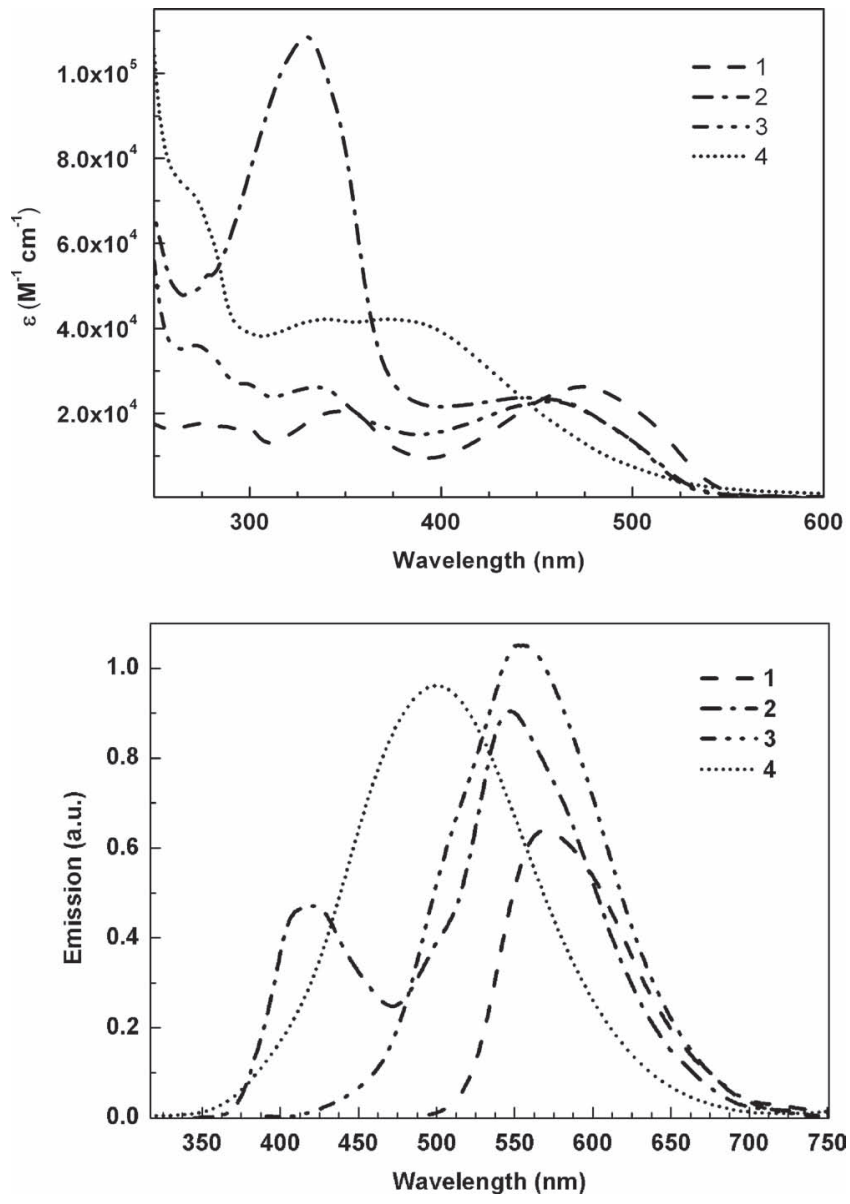

Figure 1. Absorption (top) and relative emission (bottom) of compounds $1-4$ in THF $\left(c \approx 10^{-6} \mathrm{~mol} \mathrm{~L}^{-1}\right.$ and $\left.T=298 \mathrm{~K}\right)$.

oxides. ${ }^{[22 a]}$ Moreover, this compound displays only one emission band located at $\lambda_{\mathrm{em}}=569 \mathrm{~nm}$ when excited at the band corresponding to the $\pi-\pi^{*}$ transition $\left(\lambda_{\text {ex }}=472 \mathrm{~nm}\right)$. The first generation PPV-type dendrimer 2 , with phenylenevinylene dendrons also shows two main absorption bands at $\lambda_{\max }=330 \mathrm{~nm}$ and $\lambda_{\max }=452 \mathrm{~nm}$, which can be assigned to the dendrons ${ }^{[22 \mathrm{a}]}$ and to the extended dithienophosphole core, respectively. With respect to the emission features of dendrimer 2, two maxima (at $\lambda_{\mathrm{em}}=423 \mathrm{~nm}$ and $\lambda_{\mathrm{em}}=547 \mathrm{~nm}$ ) were, however, observed when excited at $\lambda_{\text {ex }}=330 \mathrm{~nm}$ (see Figure 1). The lower energy band $\left(\lambda_{\mathrm{em}}=547 \mathrm{~nm}\right.$ ) corresponds to the emission coming from the phosphole core, as a result of an energy transfer from the branches to the core. ${ }^{[22 a]}$ On the other hand, the second peak centered at $\lambda_{\mathrm{em}}=423 \mathrm{~nm}$, which corresponds to the dendron emission, arises as a consequence of an incomplete energy transfer likely due to many factors based on Förster's mechanism. ${ }^{[25]}$ Despite the presence of these two simultaneous relaxation processes it is important to note that the energy transfer efficiency still remains in the range of $64-75 \%$. The Fréchet-type dendrimer 3 and its dimeric relative 4 present several absorption maxima in the different solvents. Both compounds exhibit an absorption band located at around $\lambda_{\max }=272 \mathrm{~nm}$ which is attributed to the 3,4,5-trisubstituted benzyloxy dendrons. ${ }^{[25 a]}$ Similar to dendrimer 2, compound 3 exhibits an absorption maximum at $\lambda_{\max }=458 \mathrm{~nm}$ corresponding to the $\pi-\pi^{*}$ transition of the central dithienophosphole. Remarkably, this band is strongly blue-shifted to $\lambda_{\max }=377 \mathrm{~nm}$ in the supramolecular structure 4 after dimerization with palladium. This is in stark contrast to non-extended dithienophosphole core that shows a $10 \mathrm{~nm}$ red shift from the oxidized derivative to the corresponding Pd-bridged dimer in both the absorption and emission features. ${ }^{[17 \mathrm{e}]}$ In this particular case, the unexpected hypsochromic shift of around $80 \mathrm{~nm}$ regardless of the nature of the solvent might come hand in hand with a perturbation in the energetic levels of the frontier orbitals due to steric congestion. In terms of emission features, no clear residual emission band coming from the branches was detected when exciting 3 at $\lambda_{\text {ex }}=$ $272 \mathrm{~nm}$, which is in contrast to dendrimer 2. Only a structureless peak at $\lambda_{\mathrm{em}}=552 \mathrm{~nm}$ originated from the central extended dithienophosphole core, with a significant energy transfer efficiency in the range of $69-84 \%$, was observed. When exciting the Pd-bridged dendrimer 4 at the benzyloxy dendrons $\left(\lambda_{\mathrm{ex}}=\right.$ $273 \mathrm{~nm})$, the compound displayed a unique and very broad emission band $\left(\lambda_{\mathrm{em}}=499 \mathrm{~nm}\right)$ that is blue-shifted with respect to the monomeric oxide compound 3. The energy transfer efficiency of this dimeric dendrimer was in the same range as those observed for the monomeric dendrimer 3 (69-89\%, depending on the solvent employed), supporting an energy transfer occurring independently into each of the two dendrimers.

Finally, the emission properties of all compounds were also measured in the solid state. Their viscous state at room temperature allowed for the straightforward preparation of thin films simply by sandwiching them between two quartz slides. Despite the fact that some structures possess large and rigid dendrons, which could inhibit the fluorescence decays in the solid state by $\pi$-stacking, ${ }^{[26]}$ it is noteworthy that all compounds showed strong photoluminescence intensity with emission maxima located in the orange-red region of the optical spectrum (see Table 1). Based on these observations it is inherently plausible that the out-of-plane phenyl group attached to the pyramidal phosphorus center is responsible for preventing self-quenching in solid state.

\subsection{Gelation Studies}

In general, organogels are entangled microscale 3D-networks that are formed as a consequence of the ability of organic molecules to trap and immobilize organic solvents through cooperative effects of non-covalent interactions, such as hydrogen bonding, $\pi-\pi$ stacking, donor-acceptor interactions, solvophobic forces, and van der Waals interactions. ${ }^{[12 a, 27]}$ As mentioned in the introduction, in order for these supramolecular assemblies to occur, the intermolecular interactions have to be carefully balanced in such a way that they ensure the molecular self-assembly, but at the same time, are weak enough to avoid the transformation into a crystalline state. It is furthermore essential that the gel-solution transitions are thermally reversible and consequently some of the physical properties associated with both states (absorption, fluorescence, light harvesting features, etc.) can also be thermally tuned, giving rise to a diverse set of intriguing applications. ${ }^{[12 a, 27,28]}$

In line with these concepts, the gelation properties of compounds 1-4 were tested in a wide range of solvents (polar, nonpolar, protic, and non-protic), as well as employing several gelation 

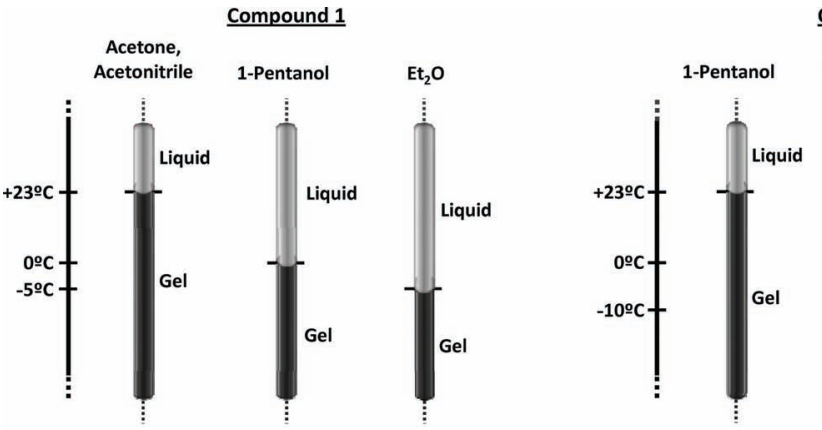

Compound 2
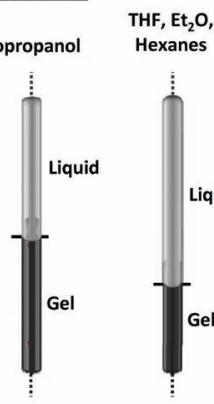

Compound 3
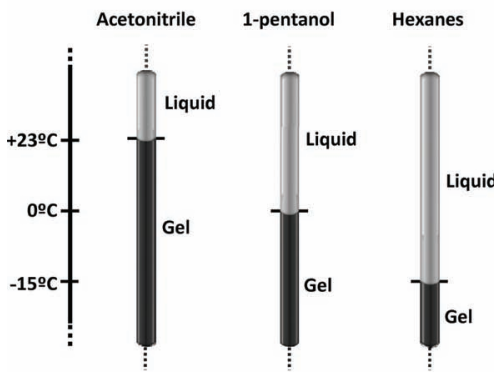

Compound 4

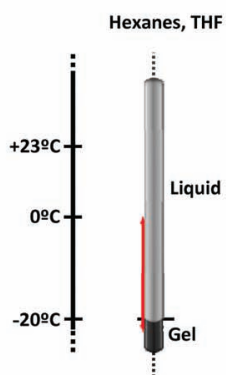

Figure 2. Summary of gelation conditions of compounds 1-4. Gels were prepared by using different concentrations and techniques (see SI, Table S1).

techniques (SI, Table S1). The gelation tests were performed in a capped test-tube and the absence of flow when turning the testtube containing the sample upside-down was used as the decisive gel formation criterion. The "generation 0" compound 1, which possesses a planar rigid central area with an out-of-plane phenyl group connected at the phosphorus atom, was found to be able to gel polar solvents such as diethyl ether $\left(\mathrm{Et}_{2} \mathrm{O}\right)$, acetone, acetonitrile and 1-pentanol (SI, Figure S6). Non-polar solvents such as hexanes, methylcyclohexane, xylenes and toluene, as well as chlorinated solvents and alcohols shorter than 1-pentanol, on the other hand, did not induce any gelation. The different gels formed in the polar solvents were found to be thermo-reversible, however, at different transition temperatures (Figure 2). In particular, compound 1 was completely suspended at room temperature in acetone and acetonitrile, at $0{ }^{\circ} \mathrm{C}$ in 1-pentanol, and at $-5^{\circ} \mathrm{C}$ in $\mathrm{Et}_{2} \mathrm{O}$.

The first generation dendrimer 2 , in which the central rigid area is extended along the PPV dendrons, was also found to gel thermoreversibly a variety of organic solvents. In either case the whole solvent volume was completely suspended as representatively shown in Figure 3.

Despite an expected higher tendency to precipitate due to the larger rigid central area, the gelation properties of 2 were comparable to those of compound 1. In this case, however, the use of alcohol solvents gave rise to the higher transition temperatures. Therefore, 1-pentanol successfully led to the formation of a gel phase at room temperature, while isopropanol induced gelation only at $0{ }^{\circ} \mathrm{C}$ (Figure 2). Ethereal $\left(\mathrm{Et}_{2} \mathrm{O}\right.$, THF) and hexanes solutions also formed gels upon cooling from room temperature to around $-10{ }^{\circ} \mathrm{C}$. However, in non-polar (methylcyclohexane, xylenes, toluene) and chlorinated $\left(\mathrm{CH}_{2} \mathrm{Cl}_{2}, \mathrm{CHCl}_{3}\right)$ solvents, dendrimer 2 was too soluble to form gels even at low temperature.
www.MaterialsViews.com

Moreover, solvents of higher polarity, such as acetone, acetonitrile, $\mathrm{MeOH}$ and $\mathrm{EtOH}$, were unable to dissolve 2 even upon boiling the solutions for several minutes.

Surprisingly, compound 3 with the flexible 3,4,5-trisubstituted benzyloxy dendrons was found to be more soluble than dendrimer 2, even though some Fréchet-type dendrimers were reported to strongly induce gelation processes. ${ }^{[29]}$ In fact, lower transition temperatures were found for THF and hexanes solutions of compound $3,\left(-25^{\circ} \mathrm{C}\right.$ and $-15^{\circ} \mathrm{C}$ respectively), and the $\mathrm{Et}_{2} \mathrm{O}$ solutions were unable to gel even at very low temperatures $\left(<-50{ }^{\circ} \mathrm{C}\right)$. Notwithstanding, acetonitrile solutions showed gelation at room temperature, and 1-pentanol solutions at $0{ }^{\circ} \mathrm{C}-$ similar to compound 1 . In the other solvents, dendrimer 3 presented a comparable behavior to that of compound 2 .

Finally, the dimeric Pd-bridged compound 4 was also exposed to gelation studies. It exhibited very low gel-solution transition temperatures and only showed gelation in hexanes and THF solutions at $-20{ }^{\circ} \mathrm{C}$. In this case, the competition between phase separation and dissolution seemed to be insufficiently balanced, leading either to the complete solubilization-even at low temperatures, or to the entire precipitation, depending on the solvent employed. This suggests that the reduced flexibility provided by the palladium bridge may suppress a constructive orientation of the molecules for a highly ordered 3D-network.

Besides the behavior observed for the dimeric derivative 4, remarkably compounds 1,2 , and 3 , which only bear the

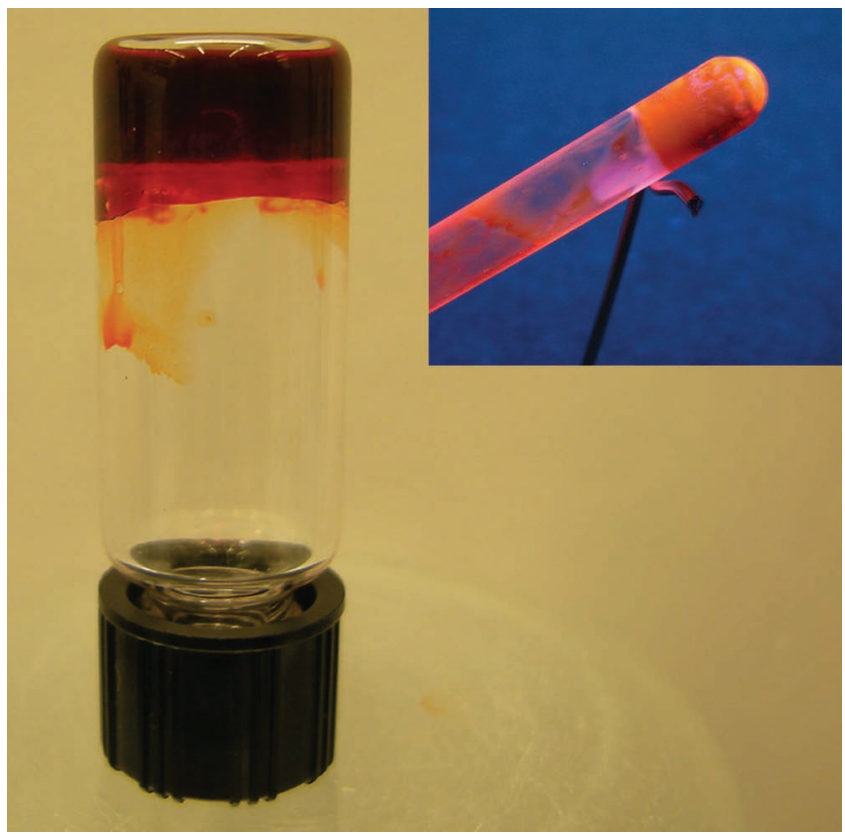

Figure 3. Gel phase of compound $\mathbf{2}$ in 1-pentanol (inset: irradiated under UV light, $366 \mathrm{~nm}$ ). 
extended dithienophosphole as common structural element, were able to gel organic solvents at room temperature independently from the size/flexible nature of their peripheral substituents. This particular discovery strongly supports the suitability of these phosphorus heterocycles for the construction of supramolecular and self-assembled architectures. Nevertheless, it is noteworthy that the flexibility of the phosphole substituents determine if a solvent is gelated, as well as the corresponding transition temperature.

Regarding the photophysical features, it is important to note that all of the gels displayed strong photoluminescence upon UV irradiation at $365 \mathrm{~nm}$ (see Figure 3, inset). On the basis of this observation, the emission spectra of the gels in different solvents were recorded. The emission wavelengths are summarized in Table S2 of the SI (see also Figure S7). In general, the emission properties of the gel phases were strongly influenced by the solvents used in the gelation process. Furthermore, a notable difference was found in the emission changes of the compounds with a central rigid area (compounds 1 and 2) and compound 3, with relatively higher flexibility within the dendrons. Thus, the emission maxima of the compounds with a more rigid scaffold (compounds 1 and 2) could be modulated in a range of approximately $\Delta \lambda_{\mathrm{em}}=30 \mathrm{~nm}$ whereas the range for compound 3 was only $\Delta \lambda_{\mathrm{em}}=10 \mathrm{~nm}$. This fact was attributed to different supramolecular structures in the 3D-networks. Indeed, this could be representatively observed by comparing the microscopic images of the xerogels of compound 1 and 3 formed from different solvents. Whereas compound 1 formed xerogels with a sponge-like morphology from acetonitrile solutions, and entangled nanotubular structures from 1-pentanol solutions

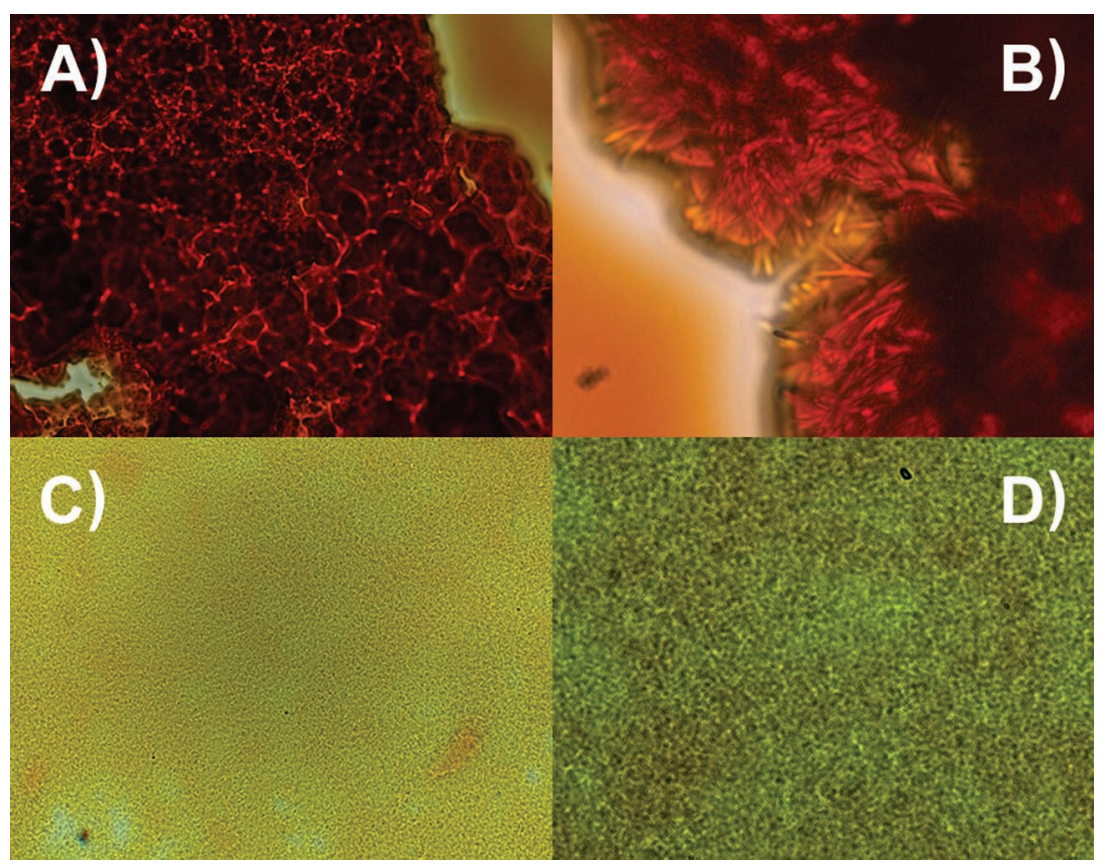

Figure 4. Images observed by confocal microscopy for the xerogels of compound 1 formed from acetonitrile $(A, 1000 \times)$ and 1-pentanol solutions (B, 400X); and xerogels of compound 3 formed from acetonitrile (C, 400x); and 1-pentanol solutions (D, 1000x). See Figure S9 (SI) for images of compound 2 .

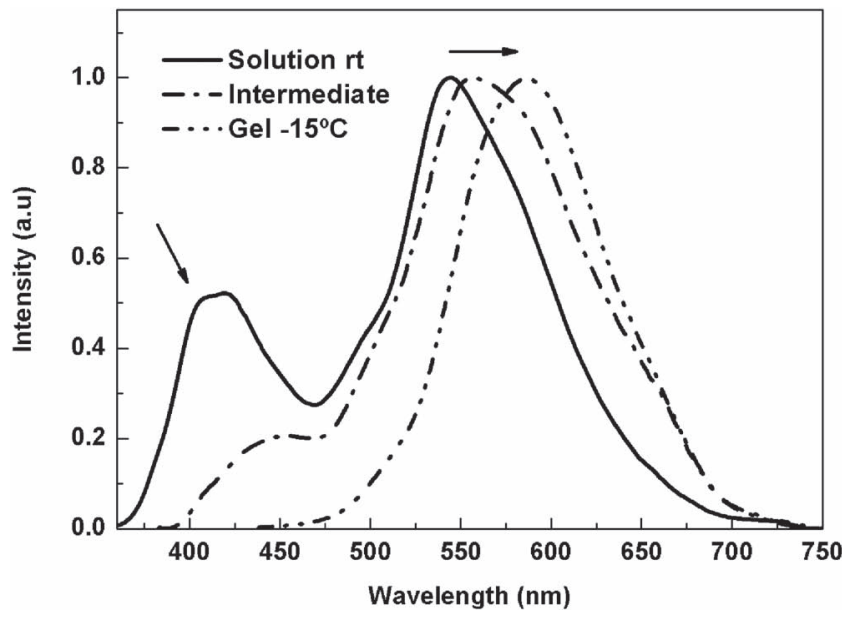

Figure 5. Normalized gel emission properties of compound 2 at different temperatures $(c=10 \mathrm{~mm}$ in $\mathrm{THF})$.

(Figure 4A-B, see also Figure S8 in SI), the xerogels of compound 3 obtained from the same solvents were found, on the contrary, to be quite comparable and with smaller morphological architectures as can be seen in Figure 4C-D (see also Figure S10 in SI).

Additionally to the aforementioned, another peculiar finding was noticed during the gelation studies of the dendrimer 2 . This derivative with larger and rigid dendrons was observed to experience dramatic color changes upon formation of the gel phase from solution. Importantly, similar features could not be observed for any of the other compounds. The emission spectra of a $10 \mathrm{~mm}$ solution in THF of compound 2 were measured at room temperature (solution), at $-15{ }^{\circ} \mathrm{C}$ (gel) and at the mid-point between these two states. The spectra are shown in Figure 5.

When the solution was cooled down, the peak located at $\lambda_{\mathrm{em}}=423 \mathrm{~nm}$ started to disappear progressively and this was accompanied by a red shift of the main band from $\lambda_{\mathrm{em}}=$ $547 \mathrm{~nm}$ to $\lambda_{\text {em }}=587 \mathrm{~nm}$. These findings are in line with an effective interaction promoted by the extended large/planar moieties. By cooling the temperature, the progressive supramolecular assembly provokes efficient intermolecular interactions which are responsible for fading out the radiative decay coming from the branches (band at $\lambda_{\mathrm{em}}=423 \mathrm{~nm}$ ), and at the same time red-shifting the emission maxima. As a result, the initial emission color originated from the sum of two emission bands $\left(\lambda_{\mathrm{em}}=\right.$ $423 \mathrm{~nm}$ and $\lambda_{\mathrm{em}}=547 \mathrm{~nm}$ ) is replaced by a unique peak $\left(\lambda_{\mathrm{em}}=587 \mathrm{~nm}\right)$ which gives rise to the final red color (see Figure 6 ). It is important to note that this process was reproducible even after several heating/cooling cycles demonstrating the thermo-reversible modulation of the emission properties by controlling the temperature. 


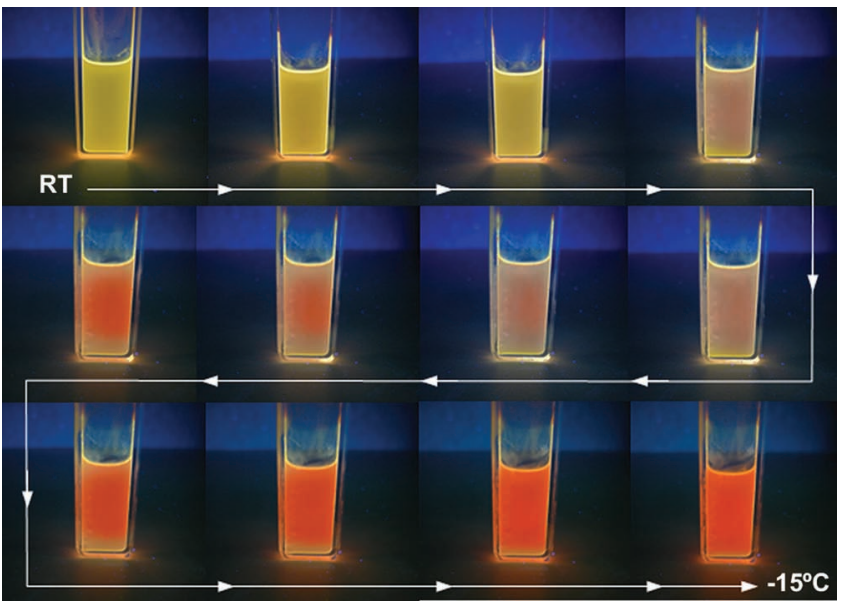

Figure 6. Fluorescence color changes of compound $\mathbf{2}$ during transition (solution $\rightarrow$ gel) from room temperature (top left) to $-15^{\circ} \mathrm{C}$ (bottom right).

\subsection{Liquid Crystal Studies}

Liquid crystals are sophisticated supramolecular self-organizations of molecules that present fluidity characteristics of liquid materials, while simultaneously displaying features associated with crystalline states, such as anisotropic properties and highly ordered organization of molecules. This "soft" ordering of molecules, in particular, has made liquid crystals very attractive for a variety of technological applications. In fact, columnar liquid crystals have demonstrated to possess very important uniaxial carrier mobilities as a consequence of their intermolecular $\pi-\pi$ overlap. ${ }^{[2 \mathrm{e}, 30]}$ Nevertheless, it is important to note that both the fluidity and the properties associated with the solid state are temperature dependent. Thus, for most common liquid crystalline materials a heat input is needed to provoke the transition from the crystalline state (non-fluidic phase) to the liquid crystalline (fluidic and ordered state), and finally to the isotropic phase (fluidic but non-ordered state).

In this context, the investigation of novel phosphorus-based liquid crystalline materials, based on compounds 1-4 appears intriguing. The thermal stability and the liquid crystalline properties of these compounds have been studied by thermogravimetric analysis (TGA), polarizing optical microscopy (POM), differential scanning calorimetry (DSC), and X-ray diffraction (XRD). The thermal and thermodynamic data are summarized in Table 2.

The thermal stability of the compounds was evaluated by thermogravimetry analysis (TGA) under a nitrogen atmosphere and showed that degradation takes place in two steps (Table 2 and Figure S11, SI). Compound 1 showed a $1.8 \%$ weight loss at $144{ }^{\circ} \mathrm{C}$, compound 2 showed a $1.8 \%$ weight loss at $137{ }^{\circ} \mathrm{C}$, compound 3 showed a $3.0 \%$ weight loss at $198{ }^{\circ} \mathrm{C}$, and compound 4 showed a $8.6 \%$ weight loss at $180{ }^{\circ} \mathrm{C}$. These studies show that these materials have the main weight loss above $350{ }^{\circ} \mathrm{C}$ and all of them start to lose weight well above the clearing point. Comparison of the different compounds revealed that the thermal stability decreases in the direction compound $\mathbf{3}>$ compound $4>$ compound $\mathbf{1}>$ compound 2 . Considering the main weight loss, on the other hand, compounds with Frechet-type dendrons (3 and 4) are thermally less stable than compounds 1 and 2 (Table 2).
Table 2. Thermal Stability, Phase Transition Temperatures, ${ }^{a)}$ and Enthalpies.

\begin{tabular}{lcc}
\hline Compd & $\begin{array}{c}\text { TCA Analysis } \\
{\left[{ }^{\circ} \mathrm{C}\right]}\end{array}$ & $\begin{array}{c}\text { Transitions } \\
{\left[{ }^{\circ} \mathrm{C}\right]\left(\left[\mathrm{KJ} \mathrm{mol}{ }^{-1}\right]\right)^{\mathrm{b})}}\end{array}$ \\
\hline 1 & $144(1.8 \%) ; 377$ & $\mathrm{C}-16(5.6) \longrightarrow \mathrm{C} 20 \longrightarrow \mathrm{Col}_{\mathrm{h}} 50^{\mathrm{c})} \longrightarrow$ । \\
& $(78.3 \%)$ & \\
2 & $137(1.8 \%) ; 382$ & $\mathrm{C}-16(33.3) \longrightarrow \mathrm{C} 54 \longrightarrow \mathrm{Col}_{\mathrm{h}} 86(1.0) \longrightarrow$ । \\
& $(75.8 \%)$ & \\
3 & $198(3.0 \%) ; 375$ & $\mathrm{C}-14(35.6) \longrightarrow \mathrm{Col}_{\mathrm{h}} 50^{\mathrm{c})} \longrightarrow \mathrm{I}$ \\
& $(78.7 \%)$ & \\
4 & $180(8.6 \%) ; 363$ & $\mathrm{C}-14(40.0) \rightarrow \mathrm{C}^{\prime} 67(29.8) \rightarrow \mathrm{C}^{\prime \prime} 124(19.0) \longrightarrow$ । \\
& $(54.0 \%)$ & \\
\hline
\end{tabular}

a) Data taken from the second scan for $\mathbf{1}, \mathbf{2}$ and $\mathbf{3}$, and from the first scan for $\mathbf{4}$ (read at the peak maximum); ${ }^{\text {b) }} \mathrm{C}, \mathrm{C}^{\prime}, \mathrm{C}^{\prime \prime}$ : crystalline phases, G: glass, Col $\mathrm{h}_{\mathrm{h}}$ : hexagonal columnar mesophase, I: isotropic liquid; ' ${ }^{c}$ Optical data.

Samples of the four phospholes were introduced between glass slides for their study by polarizing optical microscopy (POM). All the phospholes prepared show liquid crystalline behavior, except for compound 4. Under the optical microscope a birefringent mesophase appears in compounds 1, 2 and 3 (Figure 7, see also Figures S13-S15 in SI). The texture of the mesophase displayed by these compounds does not show any characteristic features and it was not possible to assign a mesophase type from the texture alone. Therefore, X-ray measurements were crucial for the mesophase assignment. Although compound 4 exhibits birefringence and some degree of fluidity at moderately high temperatures, X-ray analysis ruled out the presence of mesomorphism (see below).

The phase transitions of the phospholes were measured using differential scanning calorimetry (DSC) at a heating and cooling rate of $10{ }^{\circ} \mathrm{C} \mathrm{min}{ }^{-1}$ (Figure S12, SI). All samples were dried in a vacuum desiccator prior to analysis. Phospholes 1, 2 and 3 exhibit in the first DSC heating scan a transition corresponding to a solid-to-mesophase transition; in addition, the clearing point (mesophase-to-isotropic liquid transition) was observed in the case of compound 2. After a first heating scan to erase the thermal history of the material, subsequent heating and cooling scan thermograms are reproducible. For this reason, only the data corresponding to the second heating scan are gathered in Table 2.

For compounds 1 and 2 a glass transition could be also observed. The glassy states might derive from a partial crystallization of side chains. ${ }^{[31]}$ For phospholes $\mathbf{1}$ and $\mathbf{3}$ the mesophaseto-isotropic temperature could not be clearly detected by DSC even in the second scan and therefore the optical data taken from the microscope are given in Table 2. The DSC curves of compound 4 show several peaks that correspond to different crystal-to-crystal transitions and to the transition to the isotropic liquid, as shown by XRD.

After considering the data in Table 2, some trends can be immediately deduced. First, comparing the transition temperatures of the compound 3 (with Fréchet-type dendrons) with the compounds 1 and 2, we can observe that whereas the compounds 1 and 2 present a glass transition, compound 3 presents a direct crystal-mesophase transition. Moreover the columnar mesophase interval exhibited by compound $3\left(64^{\circ} \mathrm{C}\right)$ is broader than the columnar mesophase interval observed for compound 

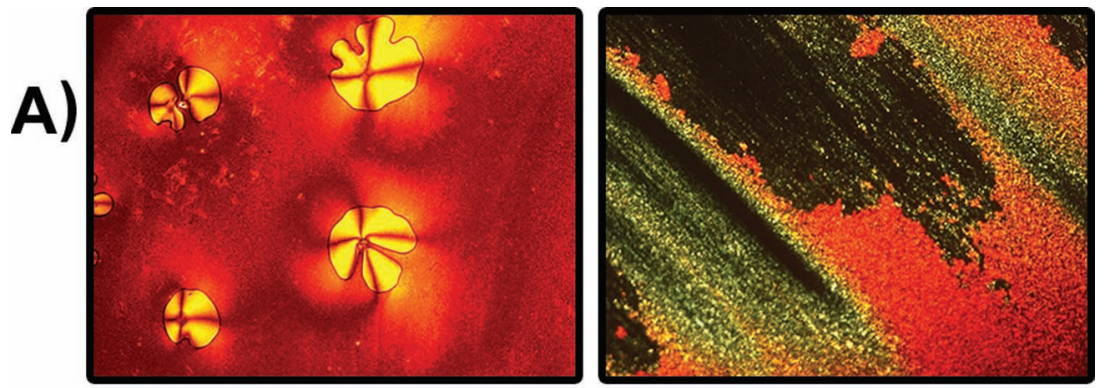

of a liquid crystal phase. On the other hand, the X-ray data of compounds $\mathbf{2}$ and $\mathbf{3}$ showed that these compounds are in the mesomorphic phase both in their virgin state and in thermally treated samples (see Table S3, SI). This conclusion was deduced in all cases from the presence of a single sharp reflection in the lowangle region and the absence of maxima in the high-angle region, except for a broad, diffuse halo typically observed for various mesophases that is characteristic of the liquid-like arrangement of hydrocarbon chains (Figure S16, SI).

The patterns were consistent with a hexagonal columnar $\left(\mathrm{Col}_{h}\right)$ mesophase and the low-angle maximum can be assigned to the (1 0) reflection from the two-dimensional hexagonal lattice. Typical X-ray patterns of perfectly ordered hexagonal columnar mesophases are known to exhibit, in the small-angle region, at least a sharp and intense maximum that is due to the intermolecular interference within the periodic arrangements of columns. The hexagonal lattice constant can be deduced from the spacing of this maximum as $a=\left(2 / 3^{1 / 2}\right) d_{\text {meas }}$. In the wide-angle region these columnar phases can show more than one scattering maximum depending on the extent to which the order extends along the column. The extra peak is attributed to the columnar periodicity (h). However, it should be noted that evidence for this columnar periodicity in the wide-angle region of the patterns was not observed in the samples measured. This absence is due to the absence of a constant stacking distance along the columns in addition to the relative shift of the columns with respect to each other.

The occurrence of X-ray diffractograms typical of a liquid crystal phase at room tempera-

$1\left(30{ }^{\circ} \mathrm{C}\right)$ and compound $2\left(32{ }^{\circ} \mathrm{C}\right)$. At the same time, the clearing temperature of $\mathbf{3}$ is lower than that of $\mathbf{2}$, which is consistent with the fact that some disorder has been introduced in the system due to the benzyl ether moiety. Comparing the effect of the generation in the phospholes 1 ("generation 0 ") and 2 (generation 1 with PPV scaffold), it can be observed that the temperature of the glass transition and the hexagonal columnar to isotropic liquid transition raise upon increasing the generation of the dendron, but the melting point (crystal to glass transition) temperature is the same.

On the other hand, as can be observed in Table 2, when the Fréchettype phosphole is complexed with palladium to give a dimer (compound 4) the liquid crystal properties are suppressed.

In order to unambiguously elucidate the structure of the mesophases observed by the above techniques, compounds 1-4 were investigated by a range of wide angle (WAXS) and small angle (SAXS) X-ray scattering experiments at variable temperatures (Table S3, SI). The X-ray patterns recorded for compound 1 at room temperature in its virgin state were characteristic of a crystalline phase. However, after thermal treatment, this compound yielded X-ray patterns at room temperature that were characteristic ture either in virgin or in thermally-treated samples is consistent with the presence of a mesomorphic glass, as confirmed by the glass transition detected by DSC for compounds 1 and 2 . In the case of compound $\mathbf{1}$, the mesomorphic phase is only obtained after cooling from the isotropic liquid. Therefore an X-ray diffractogram characteristic of a crystalline phase is recorded at $38^{\circ} \mathrm{C}$ in the first heating process (Table S3, SI) in spite of the fact that the liquid crystal phase is observed at this temperature in successive cooling or heating processes.

It should be noted that only a slight variation in the hexagonal lattice constant $a$ is observed by comparing virgin and thermally-treated samples (Table S3, SI). The same conclusion is drawn when comparing the hexagonal lattice constant $a$ at different temperatures. Furthermore no qualitative changes in the features of the X-ray diffractograms of compound 2 are observed below and above $80{ }^{\circ} \mathrm{C}$ (peak detected by DSC, Table 2), which means that the mesophase of this compound is columnar hexagonal in all the thermal range between the melting and clearing temperatures. Therefore the transition detected at $80^{\circ} \mathrm{C}$ likely corresponds only to a subtle change in the intermolecular packing or in the molecule conformation. 

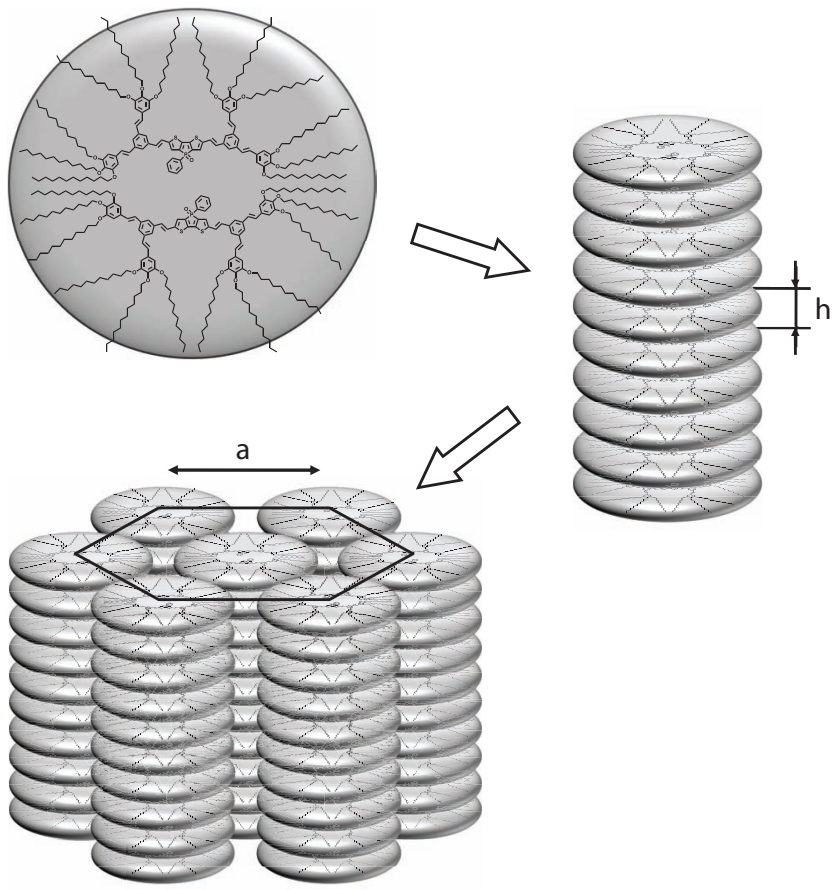

Figure 8. Schematic view of the hexagonal columnar packing. Two molecules are needed to generate the disc (three molecules in the case of compound 1).

Further insights into the mesophase structure were obtained from simple calculations based on density estimations ${ }^{[32]}$ (see $\mathrm{SI}$ ). In order to build a reasonable minimum columnar discotic entity, three molecules of $\mathbf{1}$ or two molecules of $\mathbf{2}$ and $\mathbf{3}$ are required (see Figure 8 ), giving rise to a disc with a height of about $6 \AA$ (assuming a density of $1 \mathrm{~g} \mathrm{~cm}^{-3}$ ). This information, together with the lattice parameters obtained by SAXS and WAXS, provided the basis for the dynamic simulation of the columnar arrangement. Figure 9 shows the minimized 3D-arrangement of the dendritic compound 2 in the

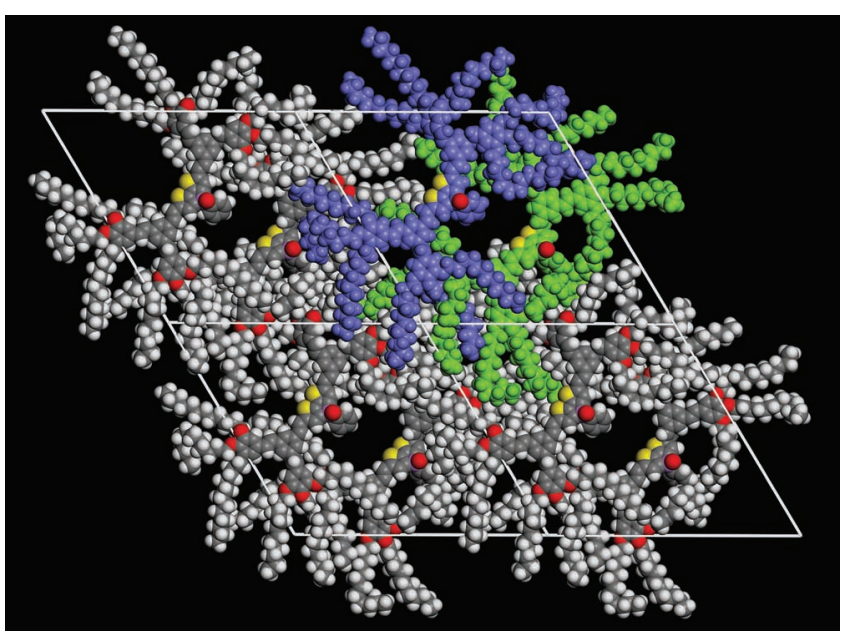

Figure 9. Molecular dynamic simulation of the columnar arrangement of compound $\mathbf{2}$. corresponding rhombohedral unit cell (see Figure S17 in the SI for compound 1).

Finally, the X-ray diffractograms recorded on compound 4 at room temperature, both in virgin and thermally-treated samples, and at high temperatures $\left(85^{\circ} \mathrm{C}, 95^{\circ} \mathrm{C}\right.$ and $\left.106{ }^{\circ} \mathrm{C}\right)$ show that this compound is not mesomorphic. Instead, it exhibits crystalline phases in all the thermal range comprised between room temperature and the transition to the isotropic liquid.

From the thermal studies it can be that phospholes 1, 2, and 3 self assemble into supramolecular entities that generate liquidcrystalline columnar arrangements. On the other hand, in dendritic complex 4, the molecule structure is not appropriate for self-assembly into a mesomorphic arrangement.

\subsection{Electrochromism Experiments}

Electrochromism is a phenomenon that involves the change of the optical properties of materials upon applying a potential. This intriguing property has proven to be especially useful and/ or promising for a wide set of applications that include mirrors, displays, windows and earth-tone chameleon materials. ${ }^{[33]}$ On the basis of the color tunability and the solid state photoluminescence established by the above-mentioned experiments, the electrochromic properties of the dendrimer 2 were also investigated. The best results were obtained by coating the compound 2 between two ITO glass electrodes and using $\mathrm{Bu}_{4} \mathrm{NClO}_{4}$ as electrolyte (see Figure S18, SI).

The neutral form of the electrochromic setup prepared from the compound 2 exhibited several absorption bands (see Figure 10, top). Located at $\lambda_{\max }=443 \mathrm{~nm}$ the $\pi-\pi^{*}$ transition corresponding to the central dithienophosphole was accompanied by a shoulder at around $\lambda_{\max }=348 \mathrm{~nm}$, and a band located at $\lambda_{\max }=303 \mathrm{~nm}$ that can be assigned to intermolecular interactions of the dendrons in the solid state. On the other hand, it is important to note that the device was transparent from $550 \mathrm{~nm}$ up to the near infrared (NIR) regions.

Upon applying a potential, $E>1.6 \mathrm{~V}$, all the absorption features evolved progressively, being relatively more predominant for the band associated with the dithienophosphole moiety. Importantly, its $\pi-\pi^{*}$ transition band was concomitantly blueshifted from $443 \mathrm{~nm}$ to $414 \mathrm{~nm}$ preserving its intensity. Simultaneously, the shoulder located around $\lambda_{\max }=348 \mathrm{~nm}$ decreased while the band at $\lambda_{\max }=303 \mathrm{~nm}$ increased slightly. In the range of the applied potentials, no additional bands were observed along the interval between the $\pi-\pi^{*}$ transition and $1000 \mathrm{~nm}$, ruling out the formation of additional and less energetic transitions. All these changes certainly exerted a strong impact on the photoluminescence response. As a consequence of the applied voltage, the photoluminescence of the film exposed to UV-light successfully changed from orange to light green as shown in Figure 10 (bottom).

To the best of our knowledge, this is the first time that the electrochromic features of phosphorus heterocycles have been tested. Although these experiments represent the preliminary steps for future and more detailed investigations, this proofof-principle study supports the potential of phosphorus-based materials to be applied in optical switching devices. 

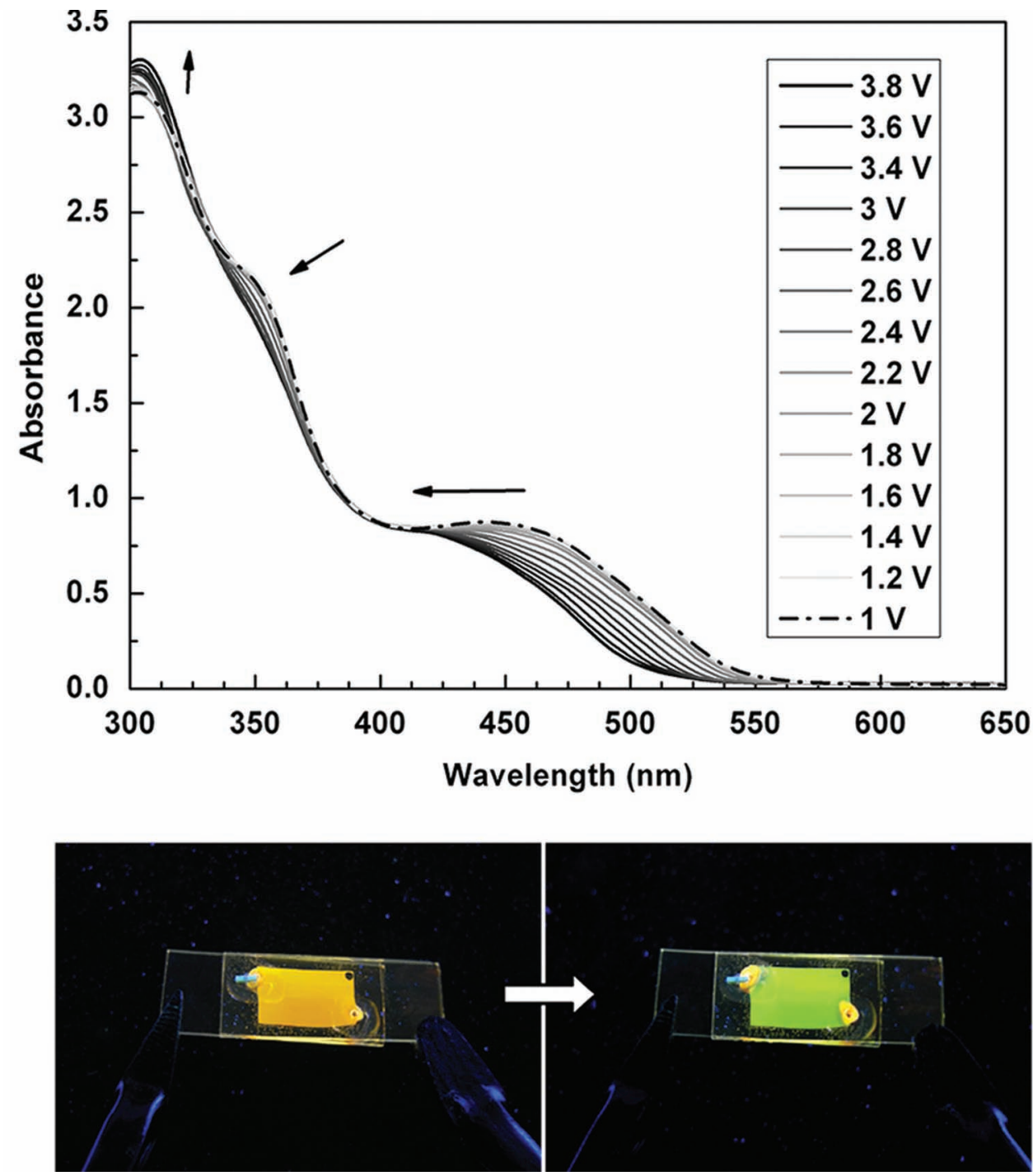

Figure 10. Top: UV-VIS spectra of compound 2 recorded upon the stepwise application of potential. Arrows indicate the direction of spectral changes. Bottom: Photoluminescence (upon exposure to UV-light) of the electrochromic device before applying potential (left) and after applying potential (right).

\section{Conclusions}

In conclusion, a series of dendritic and non-dendritic molecules based on the $\pi$-extended dithienophosphole core have been synthesized. The overall architecture of the new compounds allowed for the systematic modification of the ratio between the rigid cores/flexible fragments in order to balance the interactions that are crucial for supramolecular selforganization processes. As a result, all of these organophosphorus molecular materials exhibit the capacity to form highly fluorescent gels at different temperatures and/or solvents which depend on the flexibility of the peripheral motifs. Moreover, the photoluminescence was found to be strongly influenced by the gelation process, allowing for the modulation of the emission colors by controlling the temperature. In absence of solvent, the liquid crystalline features of the new extended phosphole derivatives were also evaluated. The compounds were found to give highly fluorescent and, in three cases, stable liquid crystalline materials at room temperature. By means of POM and XRD the self-organization was determined to be columnar hexagonal and the ability of self-assemble was shown to be tuned by appropriate tailoring of the molecular structure. Thus, this series of compounds represents an interesting example of molecules that combine liquid crystal behaviour and gelation properties. Finally, on the basis of the strong photoluminescence observed in the different states (solid, solution, and gel), the electrochromic properties were representatively investigated highlighting the switchability of the color emission of these phosphole-cored dendrimers via applying a potential. The work presented in this paper opens up new possibilities for future investigations about new multifunctional phosphorus-based materials in a variety of practical optical applications.

\section{Supporting Information}

Supporting Information is available from the Wiley Online Library or from the author. 


\section{Acknowledgements}

Financial support by the Junta de Comunidades de Castilla-La Mancha (project PCI08-0033), the Natural Science and Engineering Research Council (NSERC) of Canada, and the MICINN-FEDER (Spanish project CTQ2009-09030) is gratefully acknowledged. C.R. thanks the Junta de Comunidades de Castilla-La Mancha for a scholarship. T.B. thanks Alberta Ingenuity (now part of Alberta Innovates - Technology Futures) for a New Faculty Award. We thank the Prof. D.M. Guldi for generously allowing us to use his facilities as well as F. Werner for the SEM pictures. J.B. and M.M. thank the MICINN (Spain) for the project.

Received: May 27, 2011

Published online: September 15, 2011

[1] a) J. W. Steed, J. L. Atwood, in Supramolecular Chemistry, 2nd ed., Wiley, Chichester, 2009; b) F. J. M. Hoeben, P. Jonkheijm, E. W. Meijer, A. P. H. J. Schenning, Chem. Rev. 2005, 105, 1491; c) D. González-Rodríguez, A. P. H. J. Schenning, Chem. Mater. 2011, 23, 310 .

[2] a) J. M. Warman, M. P. de Haas, G. Dicker, F. C. Grozema, J. Piris, M. G. Debije, Chem. Mater. 2004, 16, 4600; b) B. A. Jones, M. J. Ahrens, M.-H. Yoon, A. Facchetti, T. J. Marks, M. R. Wasielewski, Angew. Chem. Int. Ed. 2004, 43, 6363; c) M. Gsönger, J. H. Oh, M. Könemann, H. W. Höffken, A.-M. Krause, Z. Bao, F. Würthner, Angew. Chem. Int. Ed. 2010, 49, 740; d) Y. Hirai, H. Monobe, N. Mizoshita, M. Moriyama, K. Hanabusa, Y. Shimizu, T. Kato, Adv. Funct. Mater. 2008, 18, 1668; e) W. Pisula, M. Zorn, J. Y. Chang, K. Müllen, R. Zentel, Macromol. Rapid Commun. 2009, 30, 1179.

[3] J. Thoen, in Physical Properties of Liquid Crystals (Eds: D. Demus, J. W. Goodby, G. W. Gray, H.-W. Spiess, V. Vill), Wiley-VCH, Weinheim, 1999, pp 208-232.

[4] Practical Handbook of Photovoltaics: Fundamentals and Applications (Eds: T. Markvart, L. Castañer), Elsevier Advanced Technology, New York, 2003.

[5] a) U. Mitschke, P. Bäuerle, J. Mater. Chem. 2000, 10, 1471; b) T. Hassheider, S. A. Benning, H.-S. Kitzerow, M.-F. Achard, H. Bock, Angew. Chem. Int. Ed. 2001, 40, 2060.

[6] a) M. Funahashi, F. Zhang, N. Tamaoki, Adv. Mater. 2007, 19, 353; b) A. J. J. M. van Breemen, P. T. Herwig, C. H. T. Chlon, J. Sweelssen, H. F. M. Schoo, S. Setayesh, W. M. Hardeman, C. A. Martin, D. M. de Leeuw, J. J. P. Valeton, C. W. M. Bastiaansen, D. J. Broer, A. R. Popa-Merticaru, S. C. J. Meskers, J. Am. Chem. Soc. 2006, 128, 2336; c) K. Oikawa, H. Monobe, K. Nakayama, T. Kimoto, K. Tsuchiya, B. Heinrich, D. Guillon, Y. Shimizu, M. Yokoyama, Adv. Mater. 2007, 19, 1864; d) I. McCulloch, M. Heeney, C. Bailey, K. Genevicius, I. MacDonald, M. Shkunov, D. Sparrowe, S. Tierney, R. Wagner, W. Zhang, M. L. Chabinyc, R. J. Kline, M. D. McGehee, M. F. Toney, Nat. Mater. 2006, 5, 328.

[7] a) T. Ichikawa, M. Yoshio, A. Hamasaki, T. Mukai, H. Ohno, T. Kato, J. Am. Chem. Soc. 2007, 129, 10662; b) B.-K. Cho, A. Jain, S. M. Gruner, U. Wiesner, Science 2004, 305, 1598.

[8] M. Zhou, T. J. Kidd, R. D. Noble, D. L. Gin, Adv. Mater. 2005, 17, 1850 .

[9] a) Molecular Gels: Materials with Self-Assembled Fibrillar Networks (Eds: R. G. Weiss, P. Terech), Springer, New York, 2006; b) A. R. Hirst, B. Escuder, J. F. Miravet, D. K. Smith, Angew. Chem. Int. Ed. 2008, 47, 8002; c) T. Ishi-i, S. Shinkai, Top. Curr. Chem. 2005, 258, 119; d) T. Naota, H. Koori, J. Am. Chem. Soc. 2005, 127, 9324; e) K. M. Anderson, G. M. Day, M. J. Paterson, P. Byrne, N. Clarke, J. W. Steed, Angew. Chem. Int. Ed. 2008, 47, 1058; f) J. W. Chung, B. K. An, S. Y. Park, Chem. Mater. 2008, 20, 6750; g) K. Sugiyasu, N. Fujita, M. Takeuchi, S. Yamada, S. Shinkai, Org. Biomol. Chem. 2003, 1, 895 .
[10] a) A. Ajayaghosh, V. K. Praveen, S. Srinivasan, R. Varghese, Adv. Mater. 2007, 19, 411; b) C. Vijayakumar, V. K. Praveen, A. Ajayaghosh, Adv. Mater. 2009, 21, 2059; c) S. S. Babu, K. K. Kartha, A. Ajayaghosh, J. Phys. Chem Lett. 2010, 1, 3413.

[11] Y. Hirai, S. S. Babu, V. K. Praveen, T. Yasuda, A. Ajayaghosh, T. KatoAdv. Mater. 2009, 21, 4029.

[12] a) S. Banerjee, R. K. Das, U. Maitra, J. Mater. Chem. 2009, 19, 6649 ; b) K. Y. Lee, D. J. Mooney, Chem. Rev. 2001, 101, 1869; c) T. Kato, Science 2002, 295, 2414; d) A. Ajayaghosh, V. K. Praveen, C. Vijayakumar, S. J. George, Angew. Chem. Int. Ed. 2007, 46, 6260; e) J. J. D. de Jong, L. N. Lucas, R. M. Kellogg, J. H. van Esch, B. L. Feringa, Science 2004, 304, 278; f) S. Srinivasan, P. A. Babu, S. Mahesh, A. AjayaghoshJ. Am. Chem. Soc. 2009, 131, 15122.

[13] a) Q. Meng, X.-H. Sun, Z. Lu, P.-F. Xia, Z. Shi, D. Chen, M.-S. Wong, S. Wakim, J. Lu, J.-M. Baribeau, Y. TaoChem. Eur. J. 2009, 15, 3474; b) J.-J. Yan, R.-P. Tang, B. Zhang, X.-Q. Zhu, F. Xi, Z.-C. Li, E.-Q. Chen, Macromolecules 2009, 42, 8451.

[14] a) T. Baumgartner, T. Neumann, B. Wirges, Angew. Chem. Int. Ed. 2004, 43, 6197; b) T. Sanji, K. Shiraishi, T. Kashiwabara, M. Tanaka, Org. Lett. 2008, 10, 2689; c) A. Fukazawa, M. Hara, T. Okamoto, E.-C. Son, C. Xu, K. Tamao, S. Yamaguchi, Org. Lett. 2008, 10, 913; d) C. Romero-Nieto, K. Kamada, D. T. Cramb, S. Merino, J. Rodríguez-López, T. Baumgartner, Eur. J. Org. Chem. 2010, 5225; e) Y. Matano, M. Nakashima, H. Imahori, Angew. Chem. Int. Ed. 2009, 48, 4002; f) A. Saito, T. Miyajima, M. Nakashima, T. Fukushima, H. Kaji, Y. Matano, H. Imahori, Chem. Eur. J. 2009, 15, 10000; g) O. Fadhel, D. Szieberth, V. Deborde, C. Lescop, L. Nyulászi, M. Hissler, R. Réau, Chem. Eur. J. 2009, 15, 4914; h) S. Graule, M. Rudolph, N. Vanthuyne, J. Autschbach, C. Roussel, J. Crassous, R. Réau, J. Am. Chem. Soc. 2009, 131, 3183; i) A. Fukazawa, H. Yamada, S. Yamaguchi, Angew. Chem. Int. Ed. 2008, 47, 5582; j) Y. Ren, Y. Dienes, S. Hettel, M. Parvez, B. Hoge, T. Baumgartner, Organometallics 2009, 28, 734.

[15] a) W. Schäfer, A. Schweig, F. Mathey, J. Am. Chem. Soc. 1976, 98, 407; b) E. Mattmann, F. Mathey, A. Sevin, G. Frison, J. Org. Chem. 2002, 67, 1208; c) E. Mattmann, F. Mercier, L. Ricard, F. Mathey, J. Org. Chem. 2002, 67, 5422; d) D. Delaere, P.-T. Nguyen-Nguyen, M. T. Nguyen, Chem. Phys. Lett. 2004, 383, 138; e) E. Mattmann, D. Simonutti, L. Ricard, F. Mercier, F. Mathey, J. Org. Chem. 2001, 66, 755; f) C. Hay, M. Hissler, C. Fischmeister, J. Rault-Berthelot, L. Toupet, L. Nyulászi, R. Réau, Chem. Eur. J. 2001, 7, 4222; g) L. Nyulászi, O. Hollóczki, C. Lescop, M. Hissler, R. Réau, Org. Biomol. Chem. 2006, 4, 996.

[16] a) T. Baumgartner, R. Réau, Chem. Rev. 2006, 106, 4681 (Correction: T. Baumgartner, R. Réau, Chem. Rev. 2007, 107, 303); b) K. D. Dillon, F. Mathey, J. F. Nixon, in Phosphorus: The Carbon Copy, Wiley, Chichester, 1998; c) H. Weyl, in Methods of Organic Chemistry, Vol. E1 Q E2: Organic Phosphorus Compounds I Q II (Ed: M. Regitz), Thieme, Stuttgart, 1982; d) F. Mathey, A. Sevin, in Molecular Chemistry of the Transition Metals, Wiley, New York, 1996.

[17] a) A. Fukazawa, Y. Ichihashi, Y. Kosaka, S. Yamaguchi, Chem. Asian J. 2009, 4, 1729; b) Y. Dienes, U. Englert, T. Baumgartner, Z. Anorg. Allg. Chem. 2009, 635, 238; c) Y. Dienes, M. Eggenstein, T. Kárpáti, T. C. Sutherland, L. Nyulászi, T. Baumgartner, Chem. Eur. J. 2008, 14, 9878; d) C. Fave, M. Hissler, K. Sénéchal, I. Ledoux, J. Zyss, R. Réau, Chem. Commun. 2002, 1674; e) T. Baumgartner, W. Bergmans, T. Kárpáti, T. Neumann, M. Nieger, L. Nyulászi, Chem. Eur. J. 2005, $11,4687$.

[18] a) M. Sauthier, B. Le Guennic, V. Deborde, L. Toupet, J.-F. Halet, R. Réau, Angew. Chem. Int. Ed. 2001, 40, 228; b) F. Leca, M. Sauthier, V. Deborde, L. Toupet, R. Réau, Chem. Eur. J. 2003, 9, 3785; C) Y. Matano, M. Nakashima, A. Saito, H. Imahori, Org. Lett. 2009, 11, 3338; d) Y. Dienes, M. Eggenstein, T. Neumann, U. Englert, T. Baumgartner, Dalton Trans. 2006, 1424; e) J. Crassous, R. Réau, Dalton Trans. 2008, 6865. 
[19] H. Tsuji, K. Sato, L. Ilies, Y. Itoh, Y. Sato, E. Nakamura, Org. Lett. 2008, 10, 2263.

[20] a) Y. Matano, T. Nakabuchi, T. Miyajima, H. Imahori, H. Nakano Org. Lett. 2006, 8, 5713; b) Y. Matano, M. Nakashima, T. Nakabuchi, H. Imahori, S. Fujishige, H. Nakano, Org. Lett. 2008, 10, 553 c) Y. Matano, T. Miyajima, N. Ochi, T. Nakabuchi, M. Shiro Y. Nakao, S. Sakaki, H. Imahori, J. Am. Chem. Soc. 2008, 130, 990.

[21] a) S. Durben, D. Nickel, R. A. Krüger, T. C. Sutherland, T. Baumgartner, J. Polym. Sci. Part A: Polym. Chem. 2008, 46, 8179; b) C. Romero-Nieto, S. Durben, I. M. Kormos, T. Baumgartner, Adv. Funct. Mater. 2009, 14, 3625; c) Z. Zhang, J. Li, B. Huang, J. Qin, Chem. Lett. 2006, 35, 958; d) C. Hay, C. Fave, M. Hissler, J. Rault-Berthelot, R. Réau, Org. Lett. 2003, 5, 3467.

[22] a) C. Romero-Nieto, S. Merino, J. Rodríguez-López, T. Baumgartner, Chem. Eur. J. 2009, 15, 4135; b) T. Sanji, K. Shiraishi, M. Tanaka, Org. Lett. 2007, 9, 3611.

[23] C. Reichardt, in Solvents and Solvent Effects in Organic Chemistry, 3rd ed.Wiley-VCH, Weinheim 2003

[24] L. D. S. Yadav, in Organic Spectroscopy, Kluwer Academic Publishers, Boston, MA, 2005

[25] a) A. Adronov, J. M. J. Fréchet, Chem. Commun. 2000, 18, 1701 b) C. Devadoss, P. Bharathi, J. S. Moore, J. Am. Chem. Soc. 1996 118,9635 .

[26] J. R. Lakowicz, in Principles of Fluorescence Spectroscopy, 3rd ed.Springer Science and Business Media LLC, New York 2006

[27] a) J. H. van Esch, B. L. Feringa, Angew. Chem. Int. Ed. 2000, 39 2263; b) P. Terech, R. G. Weiss, Chem. Rev. 1997, 97, 3133; c) K. J. C. van Bommel, A. Friggeri, S. Shinkai, Angew. Chem. Int. Ed. 2003, 42, 980

[28] a) A. Ajayaghosh, V. K. Praveen, C. Vijayakumar, Chem. Soc. Rev. 2008, 37, 109; b) N. M. Sangeetha, U. Maitra, Chem. Soc. Rev. 2005, 34, 821.
[29] a) Y. Feng, Z.-T. Liu, J. Liu, Y.-M. He, Q.-Y. Zheng, Q.-H. Fan, J Am. Chem. Soc. 2009, 131, 7950; b) Q. Chen, Y. Feng, D. Zhang, G. Zhang, Q. Fan, S. Sun, D. Zhu. Adv. Funct. Mater. 2010, 20, 36.

[30] a) S. Sergeyev, W. Pisula, Y. H. Geerts, Chem. Soc. Rev. 2007, 36, 1902; b) J. Wu, W. Pisula, K. Müllen, Chem. Rev. 2007, 107, 718; c) M. Lehmann, G. Kestemont, R. Gómez-Aspe, C. Buess-Herman, M. H. J. Koch, M. Debije, J. Piris, M. P. de Haas, J. M. Warman, M. D. Watson, V. Lemaur, J. Cornil, Y. H. Geerts, R. Gearba, D. A. Ivanov, Chem. Eur. J. 2005, 11, 3349; d) H. Eichhorn, J. Porphyr. Phthalocya. 2000, 4, 88.

[31] a) R. Beavington, M. J. Frampton, J. M. Lupton, P. L. Burn I. D. W. Samuel, Adv. Funct. Mater. 2003, 13, 211; b) M. Lehmann, C. Köhn, H. Meier, S. Renker, A. Oehlhof, J. Mater. Chem. 2006, 16, 441.

[32] a) F. Morale, R. W. Date, D. Guillon, D. W. Bruce, R. L. Finn, C. Wilson, A. J. Blake, M. Schröder, B. Donnio, Chem. Eur. J. 2003 9, 2484; b) B. Donnio, B. Heinrich, H. Allouchi, J. Kain, S. Diele, D. Guillon, D. W. Bruce, J. Am. Chem. Soc. 2004, 126, 15258.

[33] a) C. G. Granqvist, A. Azens, J. Isidorsson, M. Kharrazi, L. Kullman, T. Lindström, G. A. Niklasson, C.-G. Ribbing, D. Rönnow M. Strømme Mattsson, M. Veszelei, J. Non-Cryst. Solids 1997, 218, 273; b) D. R. Rosseinsky, R. J. Montimer, Adv. Mater. 2001, 13, 783; c) A. Michaelis, H. Berneth, D. Haarer, S. Kostromine, R. Neigl, R. Schmidt, Adv. Mater. 2001, 13, 1825; d) H. W. Heuer, R. Wehrmann, S. Kirchmeyer, Adv. Funct. Mater. 2002, 12, 89; e) G. Sonmez, H. B. Sonmez, J. Mater. Chem. 2006, 16, 2473; f) P. Anderson, R. Forchheimer, P. Tehrani, M. Berggren, Adv. Funct. Mater. 2007, 17, 3074; g) R. Baetens, B. P. Jelle, A. Gustavsen, Sol. Energ. Mat. Sol. C. 2010, 94, 87; h) S. Beaupre, A.-C. Breton, J. Dumas, M. Leclerc, Chem. Mater. 2009, 21, 1504 